Adsorption and self-assembly in methyl ester sulfonate surfactants, their eutectic mixtures and the role of electrolyte

Hui Xu, Peixun Li, Kun Ma, Rebecca J L Welbourn, Jeffrey Penfold, Robert K Thomas, David W Roberts, Jordan T Petkov, Ken Loon Choo, Soo Yee Khoo.

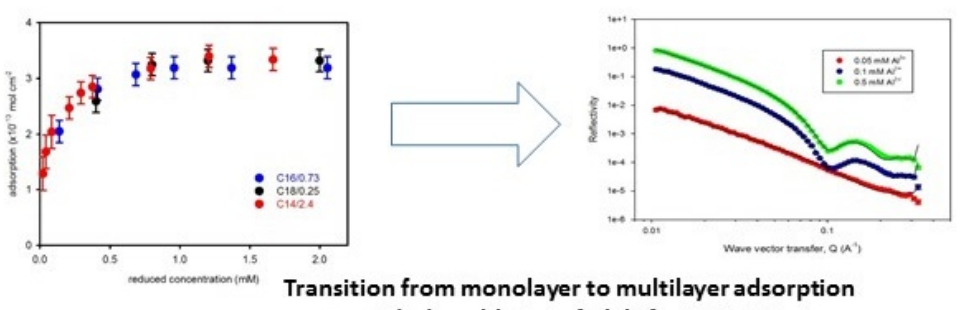

with the addition of $\mathrm{AlCl}_{3}$ for C16-MES

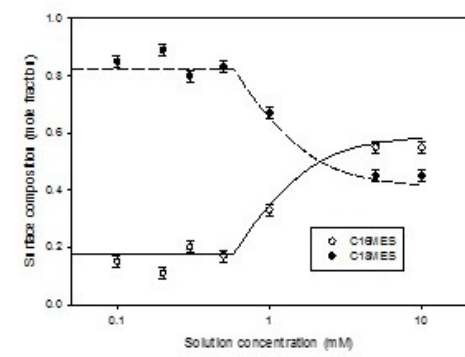

Eutectic C16-MES / C18-MES

mixture rich in

C16-MES in limit of high

concentrations 


\section{Adsorption and self-assembly in methyl ester sulfonate surfactants, their eutectic mixtures and the role of electrolyte}

Hui $\mathrm{Xu}^{1}$, Peixun $\mathrm{Li}^{2}$, Kun $\mathrm{Ma}^{2}$, Rebecca J L Welbourn², James Doutch ${ }^{2}$, Jeffrey Penfold ${ }^{2,3}$, Robert K Thomas ${ }^{3}$, David W Roberts ${ }^{4}$, Jordan T Petkov ${ }^{5}$, Ken Loon Choo $^{1}$, Soo Yee Khoo ${ }^{1}$.

1. KLK Oleo, SDN BHD, Menara KLK, Muliara Damansara, 47810, Petaling, Jaya Selanger, Malaysia

2. ISIS Facility, Rutherford Appleton Laboratory, STFC, Chilton, Didcot, OXON, OX11 0QX, UK

3. Physical and Theoretical Chemistry Laboratory, Oxford University, South Parks Road, Oxford, OX1 3QZ, UK

4. School of Pharmacy and Biomolecular SciencesLiverpool John Moores University, Liverpool, L3 3AF, UK

5. Lonza UK, GB-Blackley, Manchester, Lancs, M9 8ES, UK

Corresponding author: Jeffrey Penfold, jeff.penfold@stfc.ac.uk

Keywords: Methyl ester sulfonate surfactants, adsorption at air-water interface, self-assembly, Eutectic mixture, surface multilayers, surface and micelle mixing. 


\begin{abstract}
The $\alpha$-methyl ester sulfonate, MES, anionic surfactants are a potentially important class of sustainable surfactants for a wide range of applications. The eutectic-like Kraft point minimum in the $\mathrm{C}_{16}$ and $\mathrm{C}_{18}$-MES mixtures is an important feature of that potential. Understanding their individual adsorption properties and the surface mixing of the eutectic mixtures are key to their wider exploitation.
\end{abstract}

Neutron reflectivity has been used to investigate the adsorption at the air-water interface of the $\mathrm{C}_{16}$ and $\mathrm{C}_{18}$-MES surfactants and the eutectic mixture of $\mathrm{C}_{16}$ and $\mathrm{C}_{18}$-MES, in aqueous solution and in electrolyte. The micelle mixing of the eutectic mixture is investigated using small angle neutron scattering.

The adsorption isotherms for $\mathrm{C}_{14}$ to $\mathrm{C}_{18}$-MES are found to scale with their critical micelle concentration value. The surface and micelle compositions of the $\mathrm{C}_{16}$ and $\mathrm{C}_{18}$-MES eutectic mixture differ from the eutectic composition; with compositions in the limit of high concentrations richer in $\mathrm{C}_{16}$-MES. The mixing properties are described by the pseudo phase approximation with a repulsive interaction between the two surfactants. The impact of the multivalent ions $\mathrm{Al}^{3+}$ on the adsorption at the air-water interface results in a transition from monolayer to multilayer adsorption. 


\section{INTRODUCTION}

The major surface active ingredients in most household detergents are anionic surfactants (1, 2). The increasing demand for improved formulations to provide better detergency, enhanced performance at lower temperatures and greater tolerance to hard water has resulted in the development of a range of new anionic surfactant structures and the optimisation of anionic / non-ionic surfactant mixtures (1-4). The alkyl sulfates, especially for the longer alkyl chain lengths, precipitate readily due to the strong binding and complexation with the multivalent ions in hard water (5-7); a common problem in limiting hard water tolerance. This can be partially mitigated by co-adsorption and self-assembly with a non-ionic co-surfactant (7). The development of the alkyl benzene sulfonate, LAS, $(2,8)$, and the alkyl ethyoxy ether sulfate, SLES, (9-11) surfactants has greatly improved hard water detergency properties. LAS has for example demonstrated both improved detergency properties and biodegradability $(1,2)$.

To meet the sustainability agendas of the major detergent manufacturers there is a greater drive towards the use of surfactants prepared from renewable sustainable sources, instead of petroleum based materials (12), for greater biocompatibility and biodegradability, and for efficient operation at lower temperatures. The $\alpha$-methyl ester sulfonates, MES, anionic surfactants, prepared from renewable palm-oil based sources, have been promoted as attractive alternatives to the petroleum based counterparts (13-17). Improved hard water tolerance, greater biodegradability and better cold water detergency have been demonstrated (18-22). Hence the synthesis and purification of MES has been extensively studied and reported (15, $16,23)$, and the basic physicochemical properties, surface adsorption and self-assembly have been studied (23-26).

$\mathrm{Xu}$ et al (27) have recently reported the adsorption properties of $\mathrm{C}_{14}$-MES at the air-water interface; evaluated by surface tension, ST, and neutron reflectivity, NR, and using a synthetic route to provide better defined samples. This resulted in an adsorption isotherm and limiting adsorption amounts freer from the impact of impurities, but consistent with surface divalent counterion impurities. $\mathrm{Xu}$ et al (28) have reported the impact of electrolyte on $\mathrm{C}_{14}-\mathrm{MES}$ adsorption at the air-water interface. In $\mathrm{NaCl}, \mathrm{CaCl}_{2}$ and low concentrations of $\mathrm{AlCl}_{3}$ slightly enhanced adsorption is observed, but at higher $\mathrm{AlCl}_{3}$ concentrations surface multilayer formation occurs, ranging from a single bilayer beneath the initial monolayer at the surface to multiple bilayers. This is consistent with the more extensive studies of surface multilayer 
formation with the addition of multivalent counterions with LAS and SLES at low surfactant concentrations and outside the regime of precipitation (29-32). This was demonstrated with the addition of $\mathrm{Ca}^{2+}$ for LAS and $\mathrm{Al}^{3+}$ for SLES, in which the evolution of the extent of the surface multilayers is controlled by surfactant, and counterion concentration, and the surfactant structure. The surface multilayer formation results in persistent wetting of hydrophobic solid surfaces, substantially enhanced adsorption at interfaces, and the opportunity to deliver and provide an effective surface reservoir for other surface ingredients, such as perfumes (33).

The MES surfactants can exist with a range of alkyl chain lengths, typically from $\mathrm{C}_{12}$ to $\mathrm{C}_{18}$. Xu et al $(27,28)$ have focussed on the characterisation of the $\mathrm{C}_{14}$-MES at the air-water interface. In this paper the focus is on the adsorption of the $\mathrm{C}_{16}$ and $\mathrm{C}_{18}$-MES surfactants, and their eutectic mixture. One of the issues associated with the longer alkyl chain lengths is their relatively high Krafft temperatures, 28 and $40{ }^{\circ} \mathrm{C}$ for $\mathrm{C}_{16}$-MES and $\mathrm{C}_{18}$-MES respectively; which would suggest that the pure MES solutions would not be very effective detergents, especially at lower temperatures $(18,34)$. However the Krafft temperature of the $\mathrm{C}_{16} / \mathrm{C}_{18}$ MES mixture goes through a minimum at a temperature $\sim 15^{\circ} \mathrm{C}$ at a composition of $65 / 35$ mole ratio $\mathrm{C}_{16} / \mathrm{C}_{18}$-MES (35), and this mixture exhibits good detergency properties. A minimum in the Krafft point was reported in other anionic surfactant mixtures, in sodium dodecyl sulfate / bivalent metal dodecyl sulfate mixtures (36), in the sodium and calcium salts of other anionic surfactants such as the linear alkyl benzene sulfonates (37), in different alkyl benzene sulfonate mixtures $(38,39)$, and in myristic /palmitic acid mixtures (40); and has been likened to a eutectic point.

However little is known about the adsorption and self-assembly of such eutectic mixtures. In light of their potential importance in a range of applications the focus of this paper is on the adsorption of the eutectic mixture of $\mathrm{C}_{16} / \mathrm{C}_{18}$-MES, the individual component surfactants, and the impact of electrolyte on the adsorption, using primarily neutron reflectivity, NR. Furthermore small angle neutron scattering, SANS, is used to characterise the self-assembly of the $\mathrm{C}_{16} / \mathrm{C}_{18}$-MES eutectic mixture to primarily determine the micelle composition. The NR and SANS data are analysed and evaluated using the Pseudo phase approximation, PPA, to model the eutectic mixing behaviour. The combination of the surface and micelle compositions provides a more rigorous examination of the thermodynamics of the mixing in such systems. 


\section{EXPERIMENTAL DETAILS}

The neutron reflectivity, $\mathrm{R}(\mathrm{Q})$, was measured as a function of the wave vector transfer, $\mathrm{Q}$, perpendicular to the surface (where $\mathrm{Q}$ is defined as $\mathrm{Q}=(4 \pi \sin \theta) / \lambda, \theta$ is the grazing angle of incidence, and $\lambda$ the neutron wavelength). The measurements were made on the INTER reflectometer (41) at the ISIS pulsed neutron source in the UK; where the measurements were made at a fixed $\theta$ of $2.3^{\circ}$ and a $\lambda$ range of 1 to $15 \AA$ to cover a $Q$ range of $\sim 0.03$ to $0.3 \AA^{-1}$. The reflectivity was converted to an absolute scale by normalisation to the incident beam intensity and the reflectivity of a $\mathrm{D}_{2} \mathrm{O}$ surface. The measurements were mostly made in null reflecting water, nrw, $\left(8.8\right.$ mole $\% \mathrm{D}_{2} \mathrm{O} / 91.2$ mole $\% \mathrm{H}_{2} \mathrm{O}$, with a scattering length density, $\rho$, of 0.0 , matched to air), and using deuterium labelled or a combination of deuterium labelled and unlabelled surfactants. The measurements were made in sealed Teflon troughs, with sample volumes $\sim 25 \mathrm{~mL}$. The NR measurements for $\mathrm{C}_{16}$-MES and $\mathrm{C}_{18}$-MES were made at $30^{\circ} \mathrm{C}$ and $40^{\circ} \mathrm{C}$ respectively, and at $25^{\circ} \mathrm{C}$ for the eutectic $65 / 35$ mole ratio $\mathrm{C}_{16^{-}} / \mathrm{C}_{18}$-MES mixture. Each measurement took 20 to 30 mins; measured sequentially on a 7 position sample changer, and repeated $\sim 2-3$ times (for a total lapse time of up to 3 to 6 hours) until the reflectivity profile reached a steady state.

In the kinematic approximation (42) the neutron reflectivity is related to the square of the Fourier Transform of the scattering length density distribution, $\rho(z)$, normal to the surface; where $\rho(z)=\sum b_{i} n_{i}(z), n_{i}(z)$ is the number density distribution of species $i$ and $b_{i}$ is the scattering length (the $\sum \mathrm{b}$ values of the different components studied are listed in table 1). As the neutron scattering lengths of $\mathrm{H}$ and $\mathrm{D}$ are quite different $\left(-3.75 \times 10^{-5}\right.$ and $6.67 \times 10^{-5} \AA$ respectively) $\rho(\mathrm{z})$ can be manipulated for organic species by $\mathrm{D} / \mathrm{H}$ isotopic substitution. Hence deuterium labelling enables the reflectivity from different components at the interface to be isolated. This is the basis of the measurements here, as the reflectivity from a deuterium labelled surfactant adsorbed at a null reflecting air-water interface provides a direct estimate of the adsorbed amount (42). For monolayer surfactant adsorption the reflectivity is adequately modelled as a single layer of uniform composition using the exact expression for a thin film at the interface (42) to obtain a thickness, $d$, and scattering length density, $\rho$. The adsorbed amount is directly related to the d. $\rho$ product such that the area/molecule, A,

$$
\mathrm{A}=\sum \mathrm{b} / \mathrm{d} \rho
$$

and the adsorbed amount $\Gamma=1 / \mathrm{ANa}$, and $\mathrm{Na}$ is Avogadro's number. For a binary mixture of surfactants, 
$\mathrm{d} \rho=\sum \mathrm{b}_{1} / \mathrm{A}_{1}+\sum \mathrm{b}_{2} / \mathrm{A}_{2}$

where the subscripts 1, 2 refer to the two surfactant components. By making measurements with each component in turn deuterium labelled, $A_{1}$ and $A_{2}$ are readily determined (42). For more complex surface structures the reflectivity is usually modelled using a discreet number of layers, using the optical matrix methods (42). In modelling the NR data a flat background, typically $\sim 6$ to $8 \times 10^{-6}$, arising from the bulk scattering from the aqueous sub-phase, is included.

The SANS measurements were made on the LOQ diffractometer (43) at the ISIS pulsed neutron source. The measurements were made using the white beam time of flight method to cover a scattering vector, $\mathrm{Q}$, range (where for SANS $\mathrm{Q}$ is defined as $\mathrm{Q}=4 \pi \sin (\theta / 2) / \lambda$, and $\theta$ is the scattering angle) $\sim 0.008$ to $0.25 \AA^{-1}$. The measurements were all made in $2 \mathrm{~mm}$ path length quartz spectrophotometer cells held at $25^{\circ} \mathrm{C}$. The samples were all made in $\mathrm{D}_{2} \mathrm{O}$, using unlabelled surfactants and a combination of labelled and unlabelled surfactants for the $\mathrm{C}_{16^{-}} /$ $\mathrm{C}_{18}$-MES mixture. The data were corrected for background scattering, detector response, incident spectral distribution and converted to an absolute scattered intensity, $\mathrm{I}(\mathrm{Q})$, in $\mathrm{cm}^{-1}$, using standard procedures (44). The SANS data is modelled assuming globular or elongated micelle structures, where the scattered intensity for interacting globular polydisperse micelles is written in the 'decoupling approximation' (45) as,

$$
I(Q)=n\left[S(Q)\left|\langle F(Q)\rangle_{Q}\right|^{2}+\left\langle|F(Q)|^{2}\right\rangle_{Q}-\left|\langle F(Q)\rangle_{Q}\right|^{2}\right]
$$

where the averages denoted by $<Q>$ are averages over particles size and orientation, $n$ is the micelle number density, $S(Q)$ the structure factor, and $F(Q)$ the form factor. The micelle structure (form factor) is modelled using a standard "core and shell" model (45), as described in detail later. The inter-particle interactions are evaluated using the RMSA calculation for a repulsive screened coulombic potential between the micelle (46).

The adsorption isotherm measurements were made for $\mathrm{C}_{16}$-MES and $\mathrm{C}_{18}$-MES using deuterium labelled surfactants in nrw, in the MES concentration range of 0.1 to $10 \mathrm{mM}$. The adsorption of the $\mathrm{C}_{16} / \mathrm{C}_{18}$-MES eutectic mixture (65/35 mole ratio) was measured in the concentration range 0.1 to $10 \mathrm{mM}$ at the fixed solution composition, using the measurements $\mathrm{d}-\mathrm{C}_{16}-\mathrm{MES} / \mathrm{d}$ $\mathrm{C}_{18}-\mathrm{MES}, \mathrm{dd}, \mathrm{d}-\mathrm{C}_{16}-\mathrm{MES} / \mathrm{h}-\mathrm{C}_{18}-\mathrm{MES}, \mathrm{dh}$, and h-C $\mathrm{C}_{16}-\mathrm{MES} / \mathrm{d}-\mathrm{C}_{18}-\mathrm{MES}$, hd, in nrw. NR measurements were also made for $0.8 \mathrm{mM} \mathrm{C}_{16}$-MES (deuterium labelled surfactant in nrw) and $\mathrm{AlCl}_{3}$ concentrations from 0.05 to $0.5 \mathrm{mM}$, and for $0.2 \mathrm{mM} \mathrm{C}_{18}$-MES (deuterium labelled 
surfactant in nrw) and $\mathrm{AlCl}_{3}$ from 0.05 to $0.5 \mathrm{mM}$. Further measurements were made for the $\mathrm{C}_{16}$-MES / $\mathrm{C}_{18}$-MES eutectic mixture $\left(65 / 35\right.$ mole ratio $\mathrm{C}_{16} / \mathrm{C}_{18}$-MES) at a solution concentration of $0.25 \mathrm{mM}$ and $\mathrm{AlCl}_{3}$ concentrations from 0.02 to $2 \mathrm{mM}$ (for $\mathrm{d}_{-} \mathrm{C}_{16}$-MES / d$\mathrm{C}_{18}$-MES, dd). At $0.25 \mathrm{mM}$ surfactant concentration and $0.3 \mathrm{mM} \mathrm{AlCl}_{3}$ the measurements were made for the isotopic combinations $\mathrm{dh}$, hd, and dd in nrw. The SANS measurements were made for the eutectic $\mathrm{C}_{16}$-MES / $\mathrm{C}_{18}$-MES mixture (65/35 mole ratio) at concentrations of 5, 10 , and $20 \mathrm{mM}$, and for the isotopic combinations hh, hd, and dh in $\mathrm{D}_{2} \mathrm{O}$.

Deuterium oxide, $\mathrm{D}_{2} \mathrm{O}$, was obtained from Sigma Aldrich, and high purity water (resistivity 18.2 $\mathrm{MCcm}$ ) was used throughout. Analytical grade ( $>99.9 \%$ purity) $\mathrm{AlCl}_{3}, \mathrm{NaCl}$ and $\mathrm{CaCl}_{2}$ were used as supplied by Sigma Aldrich. All the glassware, Teflon troughs, spectrophotometer cells used for the NR and SANS measurements and sample preparation were cleaned in alkali detergent (Decon90) and extensively rinsed in ultrapure water. The sodium alkyl 2-sulfo 1methyl ester, MES, surfactants with the general formula $\mathrm{CH}_{3}\left(\mathrm{CH}_{2}\right)_{\mathrm{n}} \mathrm{CH}\left(\mathrm{SO}_{4} \mathrm{Na}\right) \mathrm{COOCH}_{3}$ (see figure 1), where $\mathrm{n}=11,13$, and 15 for $\mathrm{C}_{14}-\mathrm{MES}, \mathrm{C}_{16}$-MES and $\mathrm{C}_{18}$-MES respectively.

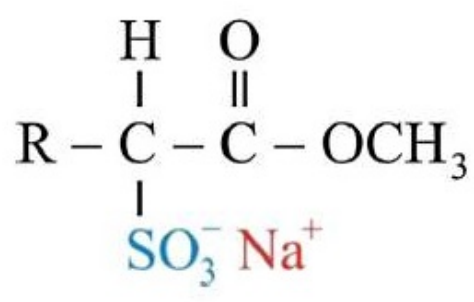

Figure 1. Structure of MES surfactant, the group labelled $\mathrm{R}$ is $\mathrm{CH}_{3}\left(\mathrm{CH}_{2}\right)_{n}$.

The MES surfactants were synthesised in two forms, with and without the alkyl chain deuterium labelled and are referred to as $\mathrm{h}-\mathrm{C}_{14}-\mathrm{MES}$ and $\mathrm{d}-\mathrm{C}_{14}-\mathrm{MES}$ etc. The synthesis and purification are described in detail elsewhere (27).

\section{RESULTS and DISCUSSION}

\section{(i) Adsorption Isotherms}

The neutron reflectivity data for $\mathrm{d}_{-} \mathrm{C}_{16} \mathrm{MES}$ and $\mathrm{d}-\mathrm{C}_{18} \mathrm{MES}$ in nrw are well described as a thin monolayer of uniform composition, and can be modelled to obtain a thickness, $\mathrm{d}$, and a 
scattering length density, $\rho$. Over the concentration range measured the mean thickness is $19 \pm 2$ $\AA$ for $\mathrm{C}_{16}$-MES and $20 \pm 2 \AA$ for $\mathrm{C}_{18}$-MES. From the $\sum \mathrm{b}$ values in table 1 the adsorbed amounts are obtained using equation 1 .

Table 1. $\sum b$ values for different components in study (used to evaluate adsorbed amounts)

\begin{tabular}{|c|c|}
\hline Component & $\sum \mathbf{b}\left(\mathbf{x 1 0}^{-\mathbf{3}} \mathbf{\AA}\right)$ \\
\hline d- $\mathrm{C}_{16} \mathrm{MES}$ & 3.37 \\
\hline h- $\mathrm{C}_{16} \mathrm{MES}$ & 0.25 \\
\hline $\mathrm{d}-\mathrm{C}_{18} \mathrm{MES}$ & 3.77 \\
\hline h- $\mathrm{C}_{18} \mathrm{MES}$ & 0.23 \\
\hline nrw & 0.0 \\
\hline
\end{tabular}

In figure $2 \mathrm{a}$ the adsorption isotherms for $\mathrm{C}_{16}$-MES and $\mathrm{C}_{18}$-MES are plotted (see table $\mathrm{S} 1$ in the Supporting Information for the corresponding data data), along with the data for $\mathrm{C}_{14}$-MES reproduced from a previous study (27). The solid lines in figure $2 \mathrm{a}$ are calculated isotherms reproduced from Danov et al (26). The differences between the directly measured isotherm for $\mathrm{C}_{14}$-MES and that derived by Danov et al (26) were discussed recently by $\mathrm{Xu}$ et al (27) and were attributed to a reevaluation of the cmc determined by Danov et al (26). The discrepancies in figure $2 \mathrm{a}$ are progressively less pronounced as the chain length increases from $\mathrm{C}_{14}$ to $\mathrm{C}_{18}$, and results from a closer agreement between the actual and derived cmc values from Danov et al (26) as the alkyl chain length increases. In figure $2 \mathrm{~b}$ the adsorption data are plotted on a reduced concentration scale, where the concentration is scaled by the surfactant cmc. Within the error of the measurements the saturation adsorption values are constant and invariant with alkyl chain length, and the isotherms overlap. This is consistent with the cmc and relative surface activity depending on the alkyl chain length. However invariance in the saturation or limiting adsorbed amount with alkyl chain length implies that the saturation adsorption is determined by the alkyl chain packing and that the headgroup plays a more secondary role. This is similar to what was reported for the SLES molecules by Xu et al (32) and for the sodium alkyl sulfates, SAS, surfactants by Varga et al (47). 


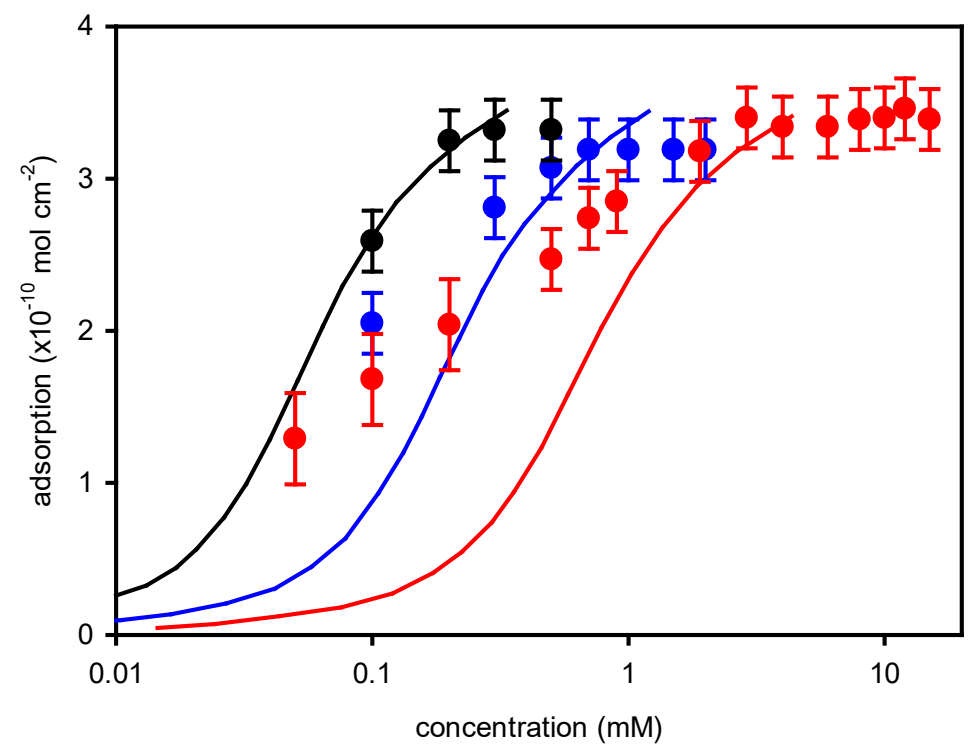

(a)

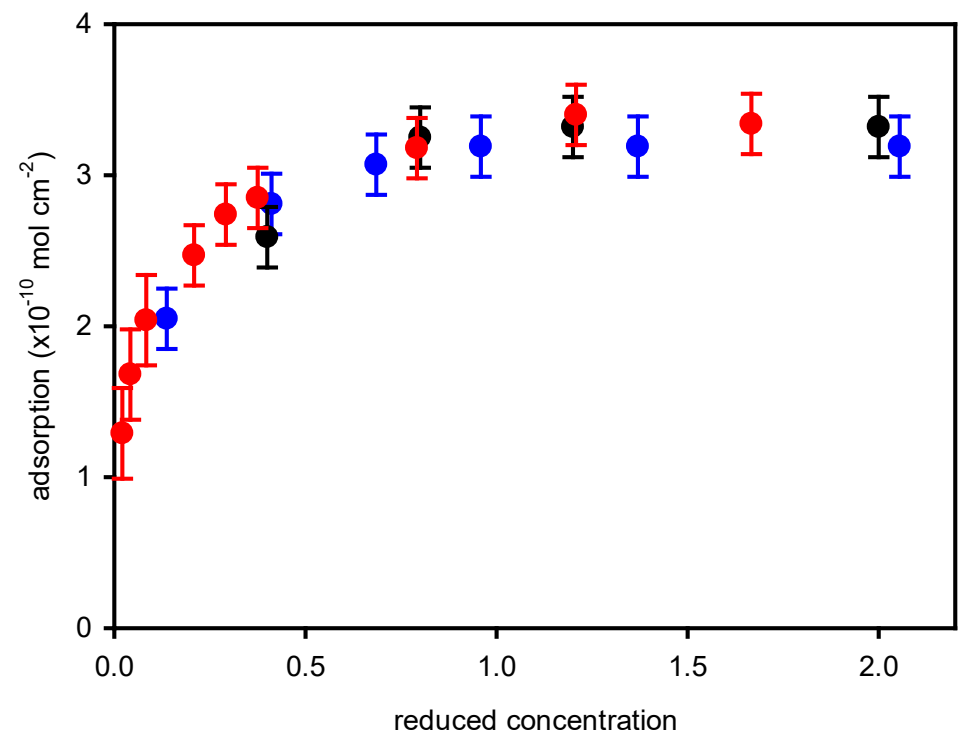

Figure 2. (a) Adsorption isotherms for $C_{14}, C_{16}$ and $C_{18}-M E S$ measured by neutron reflectivity (data for $C_{14}-M E S$ reproduced from reference 27); the solid lines are derived isotherms from

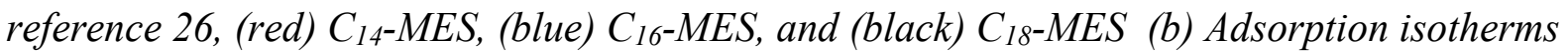
for $C_{14}, C_{16}$ and $C_{18}-M E S$ plotted on a reduced concentration scale (scaled to cmc values in legend); see legend for more details. 


\section{(ii) Impact of $\mathrm{Al}^{3+}$ on the adsorption of $\mathrm{C}_{16}$-MES and $\mathrm{C}_{18}$-MES}

The impact of $\mathrm{AlCl}_{3}$ on the adsorption of $\mathrm{C}_{14}$-MES has been extensively studied and previously reported (28). Here those measurements are extended to $\mathrm{C}_{16}$ and $\mathrm{C}_{18}-\mathrm{MES}$, and figure 3 shows the evolution of the neutron reflectivity for $0.8 \mathrm{mM} \mathrm{C}_{16}$-MES in the presence of $\mathrm{AlCl}_{3}$.

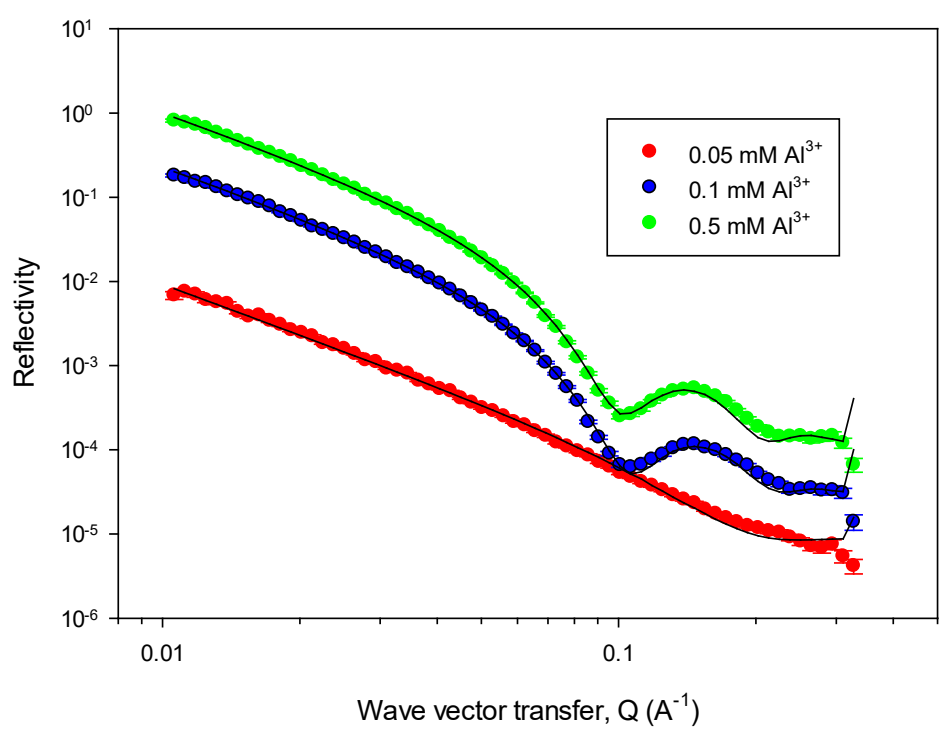

Figure 3. Neutron reflectivity for $0.8 \mathrm{mM} \mathrm{C}_{16}$-MES in 0.05, 0.1 and $0.5 \mathrm{mM} \mathrm{AlCl}_{3}$ (see legend for details). The solid lines are model calculations using the parameters in table 2 in the Supporting Information. The data for 0.1 and $0.5 \mathrm{mM} \mathrm{AlCl}_{3}$ are shifted vertically by $x 4$ and $x 16$ respectively for clarity. See legend for more details.

At the lowest $\mathrm{AlCl}_{3}$ concentration, $0.05 \mathrm{mM}$, the addition of $\mathrm{AlCl}_{3}$ results in an enhanced monolayer adsorption for $\mathrm{C}_{16}$-MES. At a surfactant concentration of $0.8 \mathrm{mM}$ the adsorbed amount increases from $\sim 3.2 \times 10^{-10} \mathrm{~mol} \mathrm{~cm}^{-2}$ to $\sim 3.8 \times 10^{-10} \mathrm{~mol} \mathrm{~cm}^{-2}$, broadly comparable to the increase observed for $\mathrm{C}_{14}$-MES (28). At the higher $\mathrm{AlCl}_{3}$ concentrations, 0.1 and $0.5 \mathrm{mM}$, the pattern of adsorption is more complex and the neutron reflectivity is dominated by a broad interference fringe at relatively higher $\mathrm{Q}$ values. The data for 0.1 and $0.5 \mathrm{mM} \mathrm{AlCl} 3$ are well described by a 3-layer model (see table 2 for the key model parameters) with a similar structure to give mean thicknesses for the three layers of $21,6,27 \pm 2 \AA$ respectively. The 3-layer model is consistent with an initial surface monolayer and a single bilayer beneath the monolayer. The structure is similar to that reported for SLES (30-32) and more recently for $\mathrm{C}_{14}$-MES (28). 
Table 2. Key model parameters for fits to NR data in figure 3, for $0.8 \mathrm{mM} C_{16}-M E S$ in $n r w$, $0.05,0.1$ and $0.5 \mathrm{mM} \mathrm{AlCl}_{3}$.

\begin{tabular}{|c|c|c|c|c|c|c|}
\hline $\begin{array}{c}\mathrm{AlCl}_{3} \\
\text { concentration } \\
(\mathbf{m M})\end{array}$ & $\begin{array}{c}\mathbf{d}_{1}( \pm 1 \\
\AA)\end{array}$ & $\begin{array}{c}\rho 1 \\
\left( \pm 0.05 \times 10^{-}\right. \\
\left.{ }^{6} \AA^{-2}\right)\end{array}$ & $\begin{array}{c}\text { d2 }( \pm 1 \\
\AA)\end{array}$ & $\begin{array}{c}\rho 2 \\
\left( \pm 0.05 \times 10^{-}\right. \\
\left.6 \AA^{-2}\right)\end{array}$ & $\begin{array}{c}\text { d3 } \mathbf{(}( \pm \mathbf{1} \\
\AA \mathbf{A})\end{array}$ & $\begin{array}{c}\rho 3 \\
( \pm 0.05 \times 10 \\
\left.{ }^{6} \AA^{-2}\right)\end{array}$ \\
\hline 0.05 & 26 & 3.10 & - & - & - & - \\
\hline 0.10 & 18 & 3.40 & 6.0 & 1.20 & 33 & 4.00 \\
\hline 0.50 & 25 & 3.40 & 7.0 & 0.90 & 21 & 5.60 \\
\hline
\end{tabular}

$d, \rho$ are the thickness and scattering length density of the layers used to model the NR data

The addition of $\mathrm{AlCl}_{3}$ to $0.2 \mathrm{mM} \mathrm{C} \mathrm{C}_{18}$-MES in the same $\mathrm{AlCl}_{3}$ concentration range resulted in precipitation, and the corresponding neutron reflectivity data were not consequently analysed quantitatively.

\section{(iii) Adsorption of C16-MES / C18-MES mixture}

As described in the Introduction a 65/35 mole ratio mixture of $\mathrm{C}_{16}$-MES / $\mathrm{C}_{18}$-MES shows a eutectic-like behaviour which is manifested as a pronounced minimum in the Krafft temperature. Here the surface adsorption of that eutectic binary mixture has been measured by neutron reflectivity in the solution concentration range of 0.1 to $10 \mathrm{mM}$. From neutron reflectivity measurements of the isotopic combinations $\mathrm{d}_{-} \mathrm{C}_{16} \mathrm{MES} / \mathrm{d}-\mathrm{C}_{18} \mathrm{MES}, \mathrm{h}-\mathrm{C}_{16} \mathrm{MES} /$ d- $\mathrm{C}_{18}$ MES and d- $\mathrm{C}_{16} \mathrm{MES} / \mathrm{h}-\mathrm{C}_{18}$ MES in nrw the total adsorption and relative amounts of $\mathrm{C}_{16^{-}}$ MES and $\mathrm{C}_{18}$-MES at the surface have been evaluated. The neutron reflectivity data for each isotopic combination are modelled as a single layer of uniform composition to give the product d.p. Using equation 2 for the binary mixture, and the $\sum b$ values in table 1, the 3 resulting simultaneous equations were solved using a simplex algorithm designed to solve a set of overdetermined linear equations (48). Figure 4a shows the evolution in the total adsorption and the relative amounts of $\mathrm{C}_{16}$-MES and $\mathrm{C}_{18}$-MES at the interface with surfactant concentration for the $65 / 35$ mole $\% \mathrm{C}_{16}$-MES / $\mathrm{C}_{18}$-MES mixture; and the key parameters and data are summarised in table 3. 


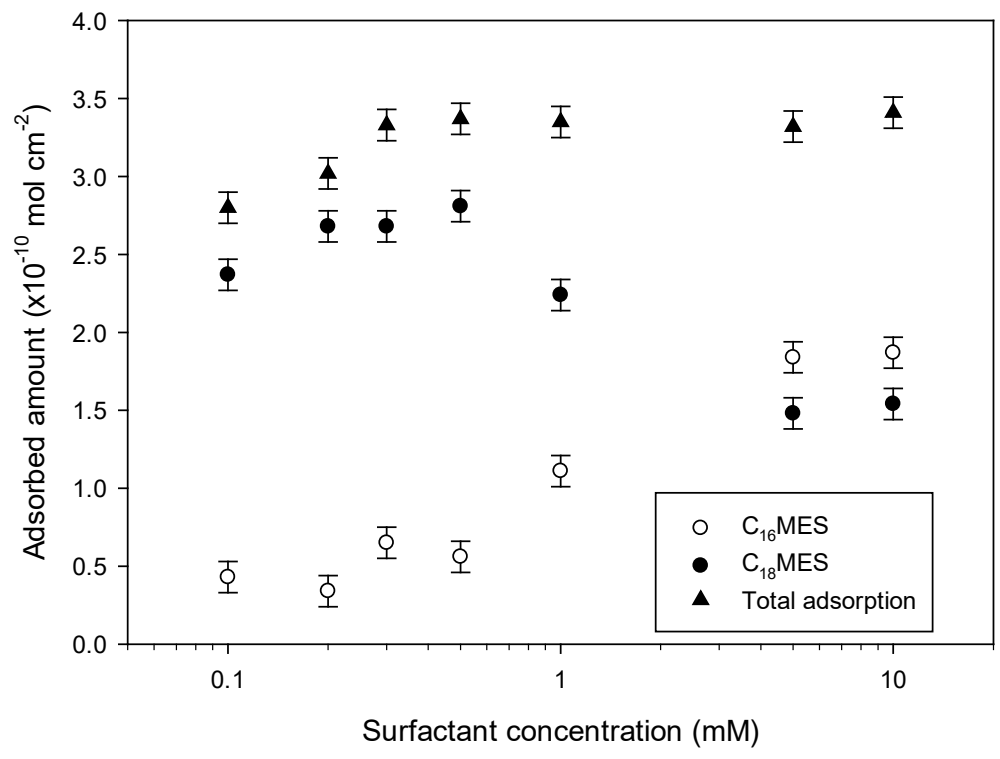

(a)

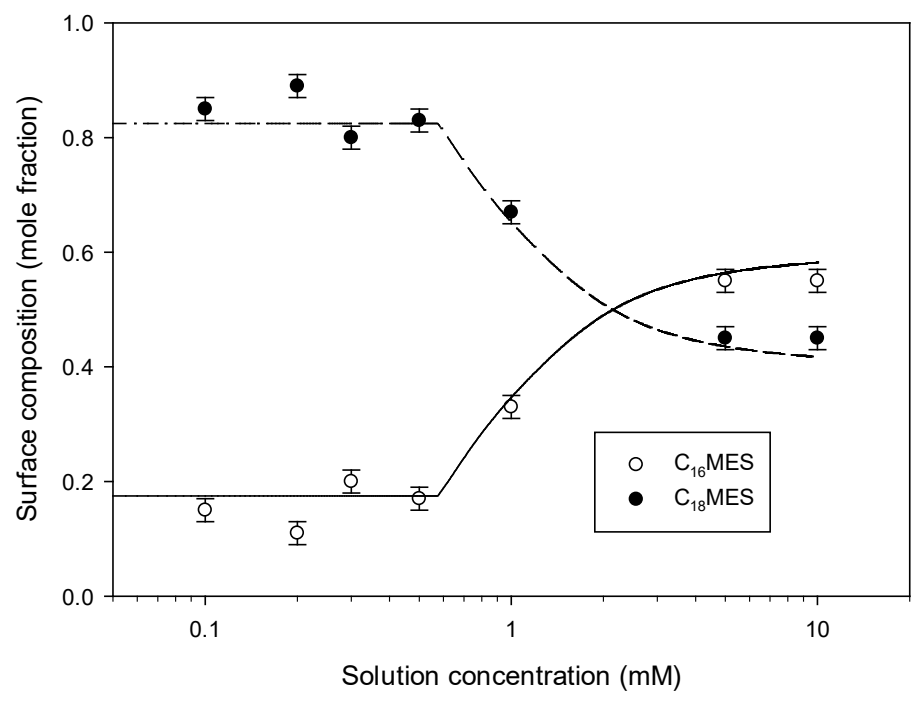

(b)

Figure 4. (a) Variation in adsorption with surfactant concentration for 65/35 mole ratio mixture of $C_{16}-M E S / C_{18}-M E S$, (see legend for details), (b) Variation in surface composition (mole fraction) with solution concentration (see legend for details). The solid and dashed lines are model calculations using the pseudo phase approximation, as described later in the discussion. 
Table 3. Adsorption data for $0.65 / 0.35$ mole ratio $C_{16} / C_{18}$-MES mixtures, from figure 4.

\begin{tabular}{|c|c|c|c|c|c|c|}
\hline \multirow{2}{*}{$\begin{array}{c}\text { Surfactant } \\
\text { concentration } \\
(\mathrm{mM})\end{array}$} & \multicolumn{2}{|c|}{$\mathrm{C}_{16-\mathrm{MES}}$} & \multicolumn{2}{|c|}{$\mathrm{C}_{18}$-MES } & \multirow{2}{*}{$\begin{array}{c}\text { Total } \\
\text { adsorption, } \\
\Gamma\left( \pm 0.05 \times 10^{-}\right. \\
\left.{ }^{10} \mathrm{~mol} \mathrm{~cm}^{-2}\right)\end{array}$} & \multirow{2}{*}{$\begin{array}{c}\text { Mole } \\
\text { fraction } \\
\text { C16-MES } \\
( \pm 0.02)\end{array}$} \\
\hline & $\mathrm{A}\left(\AA^{2}\right)$ & 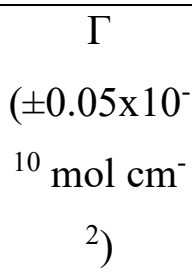 & $\mathrm{A}\left(\AA^{2}\right)$ & $\begin{array}{c}\Gamma \\
\left( \pm 0.05 \times 10^{-}\right. \\
{ }^{10} \mathrm{~mol} \mathrm{~cm}^{-} \\
2)\end{array}$ & & \\
\hline 0.1 & $309 \pm 20$ & 0.43 & $70 \pm 4$ & 2.37 & 2.80 & 0.15 \\
\hline 0.2 & 482 & 0.34 & 63 & 2.65 & 3.02 & 0.11 \\
\hline 0.3 & $254 \pm 15$ & 0.65 & 62 & 2.68 & 3.33 & 0.20 \\
\hline 0.5 & 295 & 0.56 & 59 & 2.82 & 3.37 & 0.17 \\
\hline 1.0 & $150 \pm 8$ & 1.11 & 74 & 2.24 & 3.35 & 0.33 \\
\hline 5.0 & $91 \pm 5$ & 1.84 & 112 & 1.48 & 3.32 & 0.55 \\
\hline 10.0 & 89 & 1.87 & 106 & 1.54 & 3.41 & 0.55 \\
\hline
\end{tabular}

$A$ and $\Gamma$ are the area / molecule and adsorbed amounts as defined by equations 1 and 2.

The measurements were made over the concentration range of 0.1 to $10 \mathrm{mM}$, from below to well above the mixed cmc value. The cmc values for $\mathrm{C}_{16}$-MES and $\mathrm{C}_{18}$-MES are 0.75 and 0.25 $\mathrm{mM}$ respectively. Assuming ideal mixing the mixed $\mathrm{cmc}, \mathrm{C}_{\mathrm{m}}$, can evaluated from (49),

$1 / C_{m}=\alpha / C_{1}+(1-\alpha) / C_{2}$

where $\mathrm{C}_{\mathrm{m}}$ is the mixed cmc, $\mathrm{C}_{1}$ and $\mathrm{C}_{2}$ the cmc's of the pure components and ais the mole fraction of component 1 in solution. This gives a mixed cmc for the $65 / 35$ mole ratio $\mathrm{C}_{16}$-MES / $\mathrm{C}_{18}$-MES mixture $\sim 0.44 \mathrm{mM}$. For a positive $\beta$ value of 1.4 used in the Psuedo phase approximation analysis (see later) the mixed $\mathrm{cmc}$ is $0.6 \mathrm{mM}$.

Below the mixed $\mathrm{cmc}$ the adsorption is dominated by the $\mathrm{C}_{18}$-MES adsorption, the more surface active component. The total adsorption increases with increasing surfactant concentration up to the $\mathrm{cmc}$, and around and above the $\mathrm{cmc}$ it is relatively constant and consistent with the individual adsorption of $\mathrm{C}_{16}$-MES and $\mathrm{C}_{18}$-MES (see table $\mathrm{S} 1$ ). Up to the cmc the surface composition is relatively constant with an average surface mole fraction of $\mathrm{C}_{18}$-MES $\sim 0.8$, compared to a solution composition of 0.35 . At and above the $\mathrm{cmc}$ the surface composition 
evolves more rapidly towards a composition approaching the solution composition. However it is notable that even at $\sim 20$ times the cmc the surface composition is $\sim 0.55 \mathrm{C}_{16}$-MES compared to a solution composition of 0.65 . From a surfactant concentration $\sim 5 \mathrm{mM}$ and greater the surface composition hardly changes over the limited range studied and appears to be tending towards a constant value, as observed in other mixed systems $(50,51)$. The results also show very clearly the impact of micellisation upon the evolution in the adsorption and in the surface composition; and this is broadly similar to the trends reported by Penfold et al (50) for the non-ionic surfactant mixtures of $\mathrm{C}_{12} \mathrm{E}_{3} / \mathrm{C}_{12} \mathrm{E}_{8}$ at the air-water interface. Later in the discussion a detailed evaluation of the data in the context of the pseudo phase approximation is made and discussed.

The impact of $\mathrm{AlCl}_{3}$ on the adsorption properties of the $65 / 35$ mole ratio eutectic mixture of $\mathrm{C}_{16}$-MES / $\mathrm{C}_{18}$-MES was also investigated by neutron reflectivity. Measurements were made at a fixed concentration of $0.25 \mathrm{mM}$, and $\mathrm{AlCl}_{3}$ concentrations from 0.02 to $1.0 \mathrm{mM}$. The addition of $\mathrm{AlCl}_{3}$ sufficiently lowers the mixed cmc such that the measurements at $0.25 \mathrm{mM}$ are above the cmc (the mixed $\mathrm{cmc}$ is $0.6 \mathrm{mM}$ in the absence of $\mathrm{AlCl}_{3}$ ). At the lower $\mathrm{AlCl}_{3}$ concentration, $0.02 \mathrm{mM}$, the adsorption is in the form of a monolayer, and at $\mathrm{AlCl}_{3}$ concentrations $>0.02 \mathrm{mM}$ the reflectivity data are dominated by a single interference fringe at relatively high $\mathrm{Q}$, similar to that shown in figure 3. The nature of the reflectivity is relatively constant over the $\mathrm{AlCl}_{3}$ concentration range from 0.05 to $1.0 \mathrm{mM}$. At an $\mathrm{AlCl}_{3}$ concentration of $0.3 \mathrm{mM}$ the measurements were made at 3 different contrasts, $\mathrm{d}-\mathrm{C}_{16} \mathrm{MES} / \mathrm{d}-\mathrm{C}_{18} \mathrm{dMES}$, h$\mathrm{C}_{16} \mathrm{MES} / \mathrm{d}-\mathrm{C}_{18} \mathrm{MES}$, and d-C $\mathrm{C}_{16} \mathrm{MES} / \mathrm{h}-\mathrm{C}_{18} \mathrm{MES}$ in nrw. The data are shown in figure 5 , and the solid lines are model calculations for the 3 layer model described earlier, and representing an initial monolayer with a single bilayer beneath it.

Table 4. Model parameters for fits to NR data in figure 5 for $0.25 \mathrm{mM}$ 65/35 mole ratio $C_{16}-M E S / C_{18}-M E S$ in $0.3 \mathrm{mM} \mathrm{AlCl}_{3}$.

\begin{tabular}{|c|c|c|c|}
\hline $\begin{array}{c}\text { Contrast } \\
\text { combination }\end{array}$ & $\boldsymbol{\rho}_{1}\left(\mathbf{\pm 0 . 0 5} \times \mathbf{1 0}^{\mathbf{- 6}} \AA^{\mathbf{-}^{-2}}\right)$ & $\mathbf{\rho}_{\mathbf{2}}\left(\mathbf{\pm 0 . 0 5} \times \mathbf{1 0}^{-\mathbf{6}} \AA^{-\mathbf{2}}\right)$ & $\mathbf{\rho 3}_{\mathbf{3}}\left(\mathbf{\pm 0 . 0 5} \times \mathbf{1 0}^{\mathbf{- 6}} \AA^{\mathbf{- 2}}\right)$ \\
\hline $\mathrm{dd} / \mathrm{nrw}$ & 3.5 & 1.3 & 4.3 \\
\hline $\mathrm{hd} / \mathrm{nrw}$ & 1.9 & 1.5 & 1.5 \\
\hline $\mathrm{dh} / \mathrm{nrw}$ & 2.4 & 2.9 & 1.3 \\
\hline $\mathrm{hh} / \mathrm{D}_{2} \mathrm{O}$ & 2.8 & 3.6 & 6.2 \\
\hline
\end{tabular}


The layer thicknesses, $d_{1}, d_{2}$ and $d_{3}$, are constrained to 20.0, 6.0 and 33.0 respectively for all the contrasts, and $\rho_{1}, \rho_{2}, \rho_{3}$ are scattering length densities of the layers.

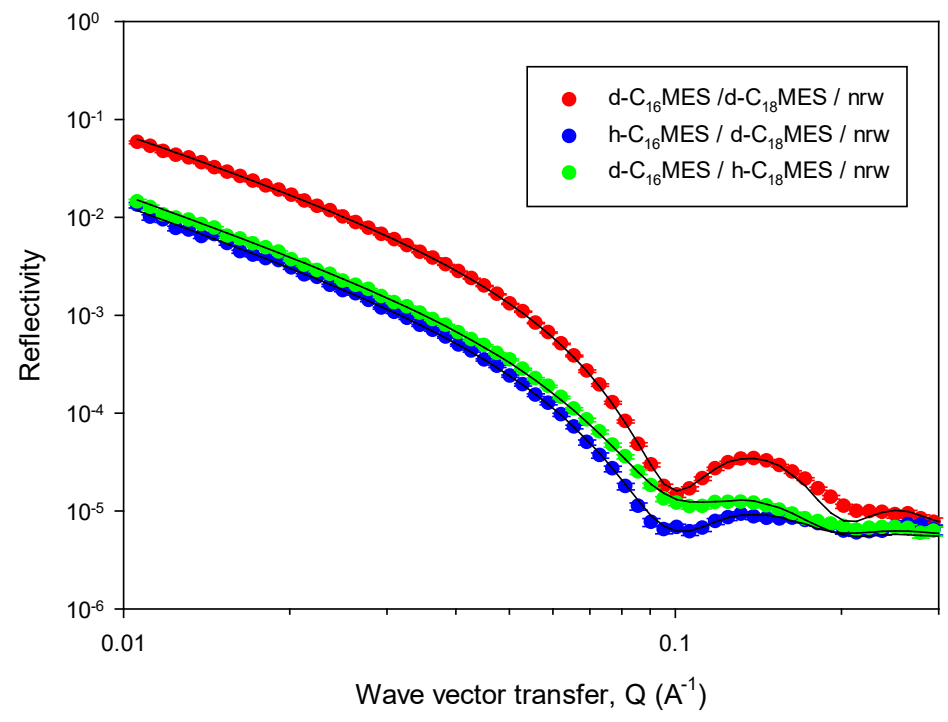

Figure 5. Neutron reflectivity data for $0.25 \mathrm{mM}$ 65/35 mole ratio $C_{16}-M E S / C_{18}-M E S$ mixture in $0.3 \mathrm{mM} \mathrm{AlCl}_{3}$, see legend for details. The solid lines are model calculations as described in the text and for the key model parameters summarised in table 4.

In analysing the 4 different reflectivity profiles the model was constrained such that the thicknesses were held the same and only the scattering length densities of the different layers were allowed to vary. The key model parameters are summarised in table 4; and the mean thicknesses of each layer were 20.0, 6.0 and $33 \pm 1 \AA$ respectively; and broadly similar to those for the data and model in figure 3. The d. $\rho$ values in the model for the isotopic combinations, $\mathrm{d}-\mathrm{C}_{16} \mathrm{MES} / \mathrm{d}-\mathrm{C}_{18} \mathrm{MES}$, and $\mathrm{h}-\mathrm{C}_{16} \mathrm{MES} / \mathrm{d}-\mathrm{C}_{18} \mathrm{MES}$ were used to estimate the composition of the initial monolayer and the bilayer beneath. For the monolayer the composition was 0.54 mole fraction $\mathrm{C}_{16}$-MES, and for the bilayer 0.53. This compares with the composition of the mixed monolayer in the absence of $\mathrm{AlCl}_{3} \sim 0.53$ mole fraction $\mathrm{C}_{16}$-MES at a roughly equivalent point above the cmc.

\section{(iv) Self-assembly of the C16-MES / C18-MES mixtures}

The self-assembly and composition of the $\mathrm{C}_{16}$-MES / $\mathrm{C}_{18}$-MES eutectic mixture has been studied using SANS at relatively low surfactant concentrations, in the concentration range 5 to $20 \mathrm{mM}$. The measurements were made for the $65 / 35$ mole ratio eutectic mixture of $\mathrm{C}_{16}$-MES $/ \mathrm{C}_{18}$-MES in the absence of electrolyte and for the isotopic combinations $\mathrm{d}-\mathrm{C}_{16} \mathrm{MES} / \mathrm{h}$ - 
$\mathrm{C}_{18} \mathrm{MES}$, $\mathrm{h}-\mathrm{C}_{16} \mathrm{MES} / \mathrm{d}-\mathrm{C}_{18} \mathrm{MES}$ and $\mathrm{h}-\mathrm{C}_{16} \mathrm{MES} / \mathrm{h}-\mathrm{C}_{18} \mathrm{MES}$ in $\mathrm{D}_{2} \mathrm{O}$ at surfactant concentrations of 5, 10 and $20 \mathrm{mM}$. The scattering data for $20 \mathrm{mM}$ surfactant concentration are shown in figure 6 . The data are consistent with globular interacting micelles, as discussed in detail later.

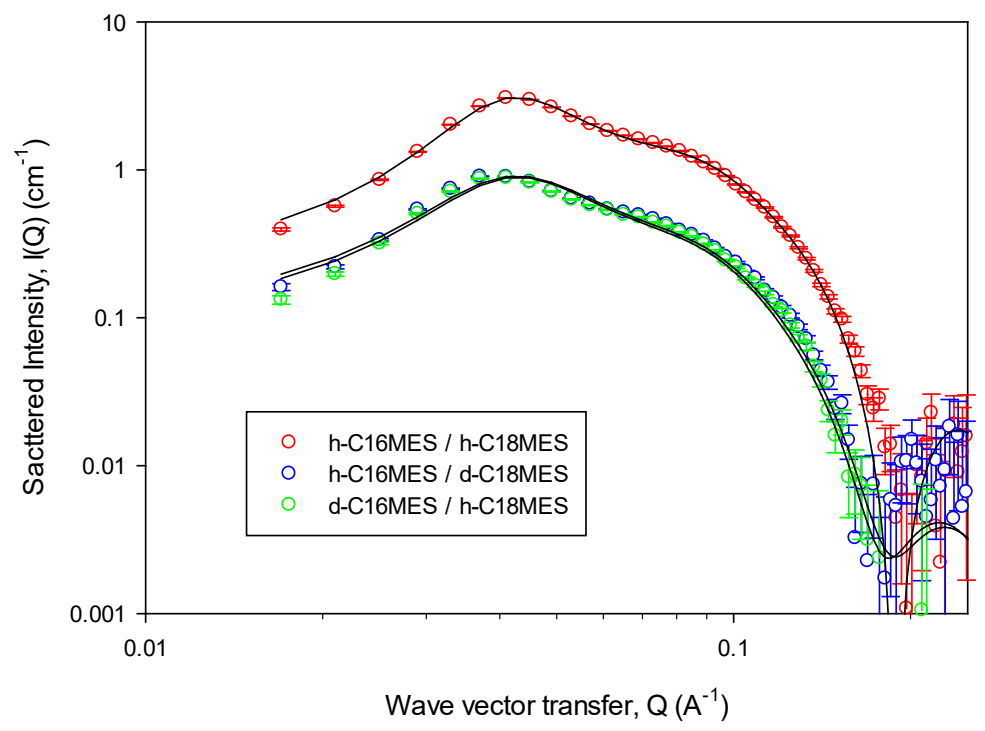

Figure 6. SANS data for $20 \mathrm{~m}$ 65/35 mole ratio $C_{16}-M E S / C_{18}-M E S$ in $D_{2} O$, and isotopic combinations $d-C_{16} M E S / h-C_{18} M E S, h-C_{16} M E S / d-C_{18} M E S$ and $h-C_{16} M E S / h-C_{18} M E S$ (see legend for details). The solid lines are model calculations as described in the text and for the key model parameters in table 6.

It was shown by Penfold et al (51) that the micelle compositions can be reliably calculated from the ratio of scattered intensities measured for different surfactant isotopic combinations. Assuming that $\mathrm{F}(\mathrm{Q})$ and $\mathrm{S}(\mathrm{Q})$ are $\sim 1.0$ at low $\mathrm{Q}$ or do not alter with isotopic content, then following Penfold et al (53),

$$
I(Q) \approx N V^{2}\left(\rho_{m}-\rho_{s}\right)^{2}
$$

and from the ratio of the intensities, $\mathrm{R}=\mathrm{I}_{\mathrm{hh}} / \mathrm{I}_{\mathrm{hd}}$ the volume fraction and mole fraction of the micelle can be obtained. As such from the hh, hd data for $\mathrm{C}_{16} / \mathrm{C}_{18}$ - MES the volume fraction, $\mathrm{V}_{\mathrm{f}}$, of $\mathrm{C}_{18}$-MES is given as,

$$
V_{f}=\frac{(\sqrt{R}-1)\left(\rho_{h-C 16}-p_{d 2 O}\right)}{\left(\rho_{h-C 18}-\rho_{h-C 16}\right)-\sqrt{R}\left(\rho_{d-C 18}-\rho_{h-C 16}\right)}
$$

and the mole fraction, $\mathrm{M}_{\mathrm{f}}$, by 


$$
M_{f}=\frac{V_{f} / V_{f o l}}{V_{f} / V_{C 18}-\left(1-V_{f}\right) / V o l_{C 16}}
$$

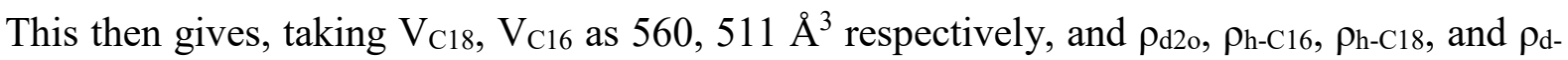
$\mathrm{C} 18$ as $6.35 \times 10^{-6}, 6.1 \times 10^{-7}, 4.2 \times 10^{-7}$, and $6.56 \times 10^{-6}$ respectively, the parameters in the table 5 below.

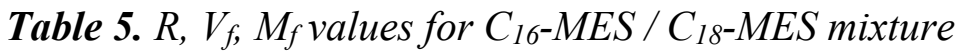

\begin{tabular}{|c|c|c|c|}
\hline $\begin{array}{c}\text { Concentration } \\
(\mathbf{m M})\end{array}$ & $\mathbf{R}(\mathbf{h h} / \mathbf{h d})$ & $\begin{array}{c}\mathbf{V}_{\mathbf{f}}\left(\mathbf{C}_{\mathbf{1 8}} \text {-MES }\right) \\
\mathbf{\pm 0 . 0 5}\end{array}$ & $\begin{array}{c}\mathbf{M}_{\mathbf{f}}\left(\mathbf{C}_{\mathbf{1 8}} \text {-MES }\right) \\
\mathbf{\pm 0 . 0 5}\end{array}$ \\
\hline 5 & & 0.42 & 0.40 \\
\hline 10 & 3.20 & 0.41 & 0.40 \\
\hline 20 & 3.10 & 0.43 & 0.41 \\
\hline
\end{tabular}

Notably in this concentration range the micelles are systematically richer in the more surface active $\mathrm{C}_{18}$-MES; but closer (and within the error of the measurements) to the solution composition than the surface (see figure $4 \mathrm{~b}$ ). A detailed evaluation of the micelle composition and its variation with concentration using the pseudo phase approximation will be presented later in the discussion along with the surface mixing.

The SANS data for the $65 / 35$ mole ratio $\mathrm{C}_{16}$-MES / $\mathrm{C}_{18}$-MES mixture are analysed using the core-shell model of interacting globular micelles developed by Hayter and Penfold (45) The core-shell model comprises of an inner core, radius R1, containing alkyl chains packed in a space filling liquid alkane density, and an outer shell, radius R2, determined by space filling and containing the headgroups and associated hydration. The inner core is constrained to a maximum dimension, lc, the fully extended alkyl chain length. For an aggregation number, $v$, which defines an inner volume larger than that defined by lc, the shape becomes elliptical (prolate ellipse) with an ellipitical ratio of ee. The inter-micellar interactions are accounted for by the RMSA screened coulombic potential which is defined by the hardsphere diameter, $\sigma,(\sigma=2 R 2)$, the surface charge, $z$, and the Debye-Hückel inverse screening length, $\kappa$, determined in the usual way by the ionic strength arising from the monomers, macroions (micelles) and any added electrolyte. Using know molecular volumes and neutron scattering lengths the form factor and structure factor can be calculated. The key refinable model 
parameters are then the micelle aggregation number, $v$, and the micelle surface charge, $\mathrm{z}$. Acceptable model fits require that the shape of the scattering is reproduced and the absolute value of the scattered intensity is predicted to within $\pm 20 \%$; that is, the scale factor, sf, can vary in the range $\sim 0.8$ to 1.2 .

The data for the three different contrasts measured are analysed separately, but with the constraint that the micelle compositions, derived in table 5 using equations 5-7, are used. The key model parameters are summarised in full in table 6.

Table 6. Key model parameters for fits to SANS data in figure 7 for 65/35 mole ratio $C_{16-}$ $\mathrm{MES} / \mathrm{C}_{18-}$ MES in $\mathrm{D}_{2} \mathrm{O}$.

(a) $20 \mathrm{mM}$

\begin{tabular}{|c|c|c|c|c|c|c|c|}
\hline $\begin{array}{c}\text { Contrast } \\
\text { combination }\end{array}$ & $v( \pm 5)$ & $z( \pm 2)$ & $\begin{array}{c}\text { R1 } \\
( \pm 0.5)\end{array}$ & $\begin{array}{c}\text { R2 } \\
( \pm 0.5)\end{array}$ & $\begin{array}{c}\text { ext } \\
( \pm 0.05)\end{array}$ & $\begin{array}{c}\text { ee } \\
( \pm 0.02)\end{array}$ & Sf \\
\hline $\mathrm{hh} / \mathrm{D}_{2} \mathrm{O}$ & 122 & 34 & 22.7 & 27.1 & 1.2 & 1.0 & 0.95 \\
\hline $\mathrm{hd} / \mathrm{D}_{2} \mathrm{O}$ & 128 & 29 & 21.9 & 26.2 & 1.1 & 1.04 & 0.86 \\
\hline $\mathrm{dh} / \mathrm{D}_{2} \mathrm{O}$ & 125 & 29 & 22.5 & 27.0 & 1.1 & 1.04 & 0.62 \\
\hline
\end{tabular}

(b) $10 \mathrm{mM}$

\begin{tabular}{|c|c|c|c|c|c|c|c|}
\hline $\begin{array}{c}\text { Contrast } \\
\text { combination }\end{array}$ & $v( \pm 5)$ & $z( \pm 2)$ & $\begin{array}{c}\text { R1 } \\
( \pm 0.5)\end{array}$ & $\begin{array}{c}\text { R2 } \\
( \pm 0.5)\end{array}$ & $\begin{array}{c}\text { ext } \\
( \pm 0.05)\end{array}$ & $\begin{array}{c}\text { ee } \\
( \pm 0.02)\end{array}$ & Sf \\
\hline $\mathrm{hh} / \mathrm{D}_{2} \mathrm{O}$ & 119 & 45 & 225 & 26.9 & 1.11 & 1.0 & 0.95 \\
\hline $\mathrm{hd} / \mathrm{D}_{2} \mathrm{O}$ & 117 & 37 & 22.3 & 26.7 & 1.12 & 1.0 & 0.76 \\
\hline $\mathrm{dh} / \mathrm{D}_{2} \mathrm{O}$ & 104 & 33 & 21.3 & 25.5 & 1.05 & 1.03 & 0.73 \\
\hline
\end{tabular}

(c) $5 \mathrm{mM}$

\begin{tabular}{|c|c|c|c|c|c|c|c|}
\hline $\begin{array}{c}\text { Contrast } \\
\text { combination }\end{array}$ & $\mathbf{v}( \pm \mathbf{5})$ & $\mathbf{z}( \pm \mathbf{2})$ & $\begin{array}{c}\mathbf{R} 1 \\
\mathbf{(} \mathbf{0 . 5})\end{array}$ & $\begin{array}{c}\mathbf{R 2} \\
\mathbf{( \pm \mathbf { 0 . 5 } )}\end{array}$ & $\begin{array}{c}\text { ext } \\
( \pm \mathbf{0 . 0 5})\end{array}$ & $\begin{array}{c}\text { ee } \\
(\mathbf{\pm 0 . 0 2})\end{array}$ & Sf \\
\hline $\mathrm{hh} / \mathrm{D}_{2} \mathrm{O}$ & 110 & 58 & 21.8 & 26.1 & 1.09 & 1.0 & 0.91 \\
\hline $\mathrm{hd} / \mathrm{D}_{2} \mathrm{O}$ & 112 & 61 & 22.0 & 26.4 & 1.10 & 1.0 & 0.85 \\
\hline $\mathrm{dh} / \mathrm{D}_{2} \mathrm{O}$ & 112 & 55 & 22.0 & 26.2 & 1.10 & 1.0 & 0.65 \\
\hline
\end{tabular}


The model parameters $v, z, R 1, R 2$, ee, ext, and $s f$ are defined in the main text.

The mean values for $v, \delta$ and ee at 20,10 and $5 \mathrm{mM}$ are $123,113,115 \pm 5,0.25,0.35,0.5 \pm 0.02$, and $1.05,1.01,1.00 \pm 0.01$ respectively. Due to the larger value for lc $\left(19.7\right.$ and $21.7 \AA$ for $\mathrm{C}_{16}$ and $\mathrm{C}_{18}$ alkyl chain lengths, compared to $16.7 \AA$ for dodecyl alkyl chains such as in SDS and SLES), and an additional model parameter, ext, the $\mathrm{C}_{16}$-MES / $\mathrm{C}_{18}$-MES mixed micelles remain almost spherical (ee $\sim 1.0$ ), even though the aggregation number is $>100$. The parameter ext allows for the packing constraints of the inner core described earlier to be relaxed $(29,39$, 52 ), enabling the inner core dimension to vary from lc to lc.ext. For the $\mathrm{C}_{16} / \mathrm{C}_{18}$-MES mixtures ext varies from 1.05 to 1.2. The aggregation number is roughly constant over the concentration range explored, increasing only slightly as the concentration increases from 5 to $20 \mathrm{mM}$. Although still globular the micelles have a larger aggregation number by comparison with other broadly similar anionic surfactants, SDS and SLES, due to the increased alkyl chain length. The degree of ionisation, $\delta$, is $\sim 0.25$ at the higher concentration of $20 \mathrm{mM}$, similar to that for SDS $(45,52)$, but notably larger than was observed for SLES (53). It increases significantly as the concentration decreases towards the $\mathrm{cmc}$, and at $5 \mathrm{mM} \delta$ is $\sim 0.5$. In general $\delta$ is observed to increase as the surfactant concentration decreases, as reported for SDS and a range of cationic surfactants $(45,52)$.

\section{DISCUSSION}

The adsorption isotherms for $\mathrm{C}_{16}$-MES and $\mathrm{C}_{18}$-MES are compared with that previously reported for $\mathrm{C}_{14}$-MES (27) in figure 2. The two key features of the isotherms and their comparison with the isotherm for $\mathrm{C}_{14}$-MES are their high degree of overlap when scaled to their respective cmc values and the lack of slope in the isotherm above the cmc.

As described earlier this overlap of the scaled isotherms and the invariance in the saturation adsorption values with alkyl chain length has been observed in other homologous series of anionic surfactants, notably the SLES surfactant with alkyl chain variations from 10 to 16 (32) and for the alkyl sulfates with alkyl chain variations from 8 to 14 (47). This is interpreted as implying that the saturated adsorption or limiting area / molecule is determined by the alkyl chain packing and the headgroup plays a more secondary role. This is not always the case and for the alkyl trimethyl ammonium cationic surfactants this is only the case when the alkyl chain length reaches a critical length (42).

The lack of slope in the isotherms above the cmc was also reported for the SLES surfactants $(31,32)$ where a detailed comparison with SDS in the presence and absence of electrolyte was 
made (54). For SDS the adsorption continues to increase significantly above the $\mathrm{cmc}$ and it was demonstrated (54) that this was associated with a change in the mean activity due to a change in the degree of dissociation of the micellar phase. In contrast SLES, which has an almost constant adsorption above the cmc, has a much lower degree of dissociation and a relatively small change in the mean activity as the cmc increases above the cmc (54). The impact of $\mathrm{NaCl}$ on the saturation adsorption for $\mathrm{C}_{14}$-MES, SLES and SDS was discussed by Xu et al $(27,28)$, and smaller increases in the saturation adsorption are observed for SLES and $\mathrm{C}_{14}$-MES compared to SDS. This and the invariance in the adsorption above the cmc was attributed to the lower level of dissociation at the surface for SLES; and implies also a similar lower degree of dissociation for $\mathrm{C}_{14}$-MES, $\mathrm{C}_{16}$-MES and $\mathrm{C}_{18}$-MES. The $\mathrm{C}_{16}$-MES and $\mathrm{C}_{18}$-MES solution structures were not measured separately, however analysis of the SANS data for the $\mathrm{C}_{16} / \mathrm{C}_{18}$ MES mixture gives $\delta$ values similar to SDS. The similarity between the MES and SDS micelle degrees of ionisation implies that for these MES surfactants the degree of counterion dissociation is different at the surface and in the micellar phase; and reflects the more complex headgroup structure of the MES surfactant compared to SDS and SLES.

The impact of $\mathrm{AlCl}_{3}$ on the surface adsorption properties of $\mathrm{C}_{14}$-MES was extensively studied and reported by $\mathrm{Xu}$ et al (28). With increasing $\mathrm{AlCl}_{3}$ concentration the surface adsorption evolved from a monolayer to surface multilayer formation with discreet numbers of bilayers, $\mathrm{n}$, from 1 to 3 , to eventually multilayer structures with large values of $\mathrm{n}, \geq 20$, at higher $\mathrm{AlCl}_{3}$ concentrations. It was shown that the evolution in the surface structure depended upon the surfactant and counterion concentrations. The structural evolution and associated surface phase diagram for $\mathrm{C}_{14}$-MES exhibited all the features previously illustrated for $\operatorname{SLES}(31,32)$ but showed how further manipulating the headgroup structure can impact upon the detailed pattern of the surface structure evolution. Xu et al (32) showed the impact of increasing the alkyl chain length and hence the solubility of the SLES surfactant on the surface structure in the presence of $\mathrm{AlCl}_{3}$; and the closer proximity of the solubility limit and precipitation has a significant impact. Compared to the $\mathrm{C}_{10}$ and $\mathrm{C}_{12}$ alkyl chain length SLES surfactants the $\mathrm{C}_{14}$ and $\mathrm{C}_{16}$ chain length SLES surfactants exhibit a narrower region of multilayer formation, with a decrease in the surface ordering at higher $\mathrm{AlCl}_{3}$ concentrations due to precipitation such that for the $\mathrm{C}_{16}$ chain length the surface eventually reverts to a monolayer. This results from the surface now being in equilibrium with a more dilute solution phase. For the $\mathrm{C}_{16}$ and $\mathrm{C}_{18}$-MES the closer proximity of precipitation in the presence of $\mathrm{AlCl}_{3}$ has a broadly similar impact to the longer alkyl chain length SLES surfactants; but in detail there are some notable differences. For $\mathrm{C}_{16^{-}}$ 
MES at a surfactant concentration of $0.8 \mathrm{mM}$ and for $\mathrm{AlCl}_{3}$ concentrations from 0.1 to $0.5 \mathrm{mM}$ the surface structure changes from a monolayer in the absence of $\mathrm{AlCl}_{3}$ and at $0.005 \mathrm{mM} \mathrm{AlCl}_{3}$ to a three layer structure, corresponding to an initial monolayer and a single bilayer beneath, which does not change over that $\mathrm{AlCl}_{3}$ concentration range. For $\mathrm{C}_{14}$-MES (28) and SLES (31, 32), at a similar surfactant concentration and $\mathrm{AlCl}_{3}$ concentration range a more extensive evolution in the surface structure, extended multilayer structures and a region with discrete small numbers of bilayers, are observed. For $\mathrm{C}_{18}$-MES at a surfactant concentration of $0.2 \mathrm{mM}$ and over the same $\mathrm{AlCl}_{3}$ concentration range the reflectivity is dominated entirely by the impact of precipitation in the bulk solution. Hence for $\mathrm{C}_{16}$-MES the absence of the more extended surface structures and the occurrence of only a three layer structure, and the onset of precipitation for $\mathrm{C}_{18}$-MES before any surface ordering occurs contrasts strongly with the observations for $\mathrm{C}_{14}$-MES $(28)$ and $\operatorname{SLES}(31,32)$. This implies that for the addition of $\mathrm{AlCl}_{3}$ as the alkyl chain length increases the onset of precipitation occurs more readily for the MES than for the SLES surfactants. This is attributed to the headgroup structure that must disfavour the binding of the $\mathrm{Al}^{3+}$ ions within the surface plane and the bridging across layers which results in the attractive force which drives the surface multilayer formation in SLES. This provides an important insight into how the nature of the headgroup geometry affects the counterion binding and the evolution in the surface structure.

The surfactant mixing for the $\mathrm{C}_{16} / \mathrm{C}_{18}$-MES mixture at a fixed solution composition of $65 / 35$ mole ratio $\mathrm{C}_{16} / \mathrm{C}_{18}$-MES, the eutectic mixture, has been measured at the air-water interface using NR over the concentration range of 0.1 to $10 \mathrm{mM}$, from below to well above the mixed cmc, see figure 4. The micelle composition for the same solution composition has been measured by SANS in the concentration range of 5 to $20 \mathrm{mM}$, see tables 5 and 6 and figure 7 .

Table 7. Pseudo phase approximation model parameters for $C_{16}-M E S / C_{18}-M E S$ micelle and surface mixtures.

C16-MES: Area/molecule at $\mathrm{cmc}=50 \AA^{2}, \mathrm{Cmc}=0.73 \mathrm{mM}$, Surface tension at $\mathrm{cmc}=37 \mathrm{mN} / \mathrm{m}$

C18-MES: Area/molecule at $\mathrm{cmc}=52 \AA^{2}, \mathrm{Cmc}=0.25 \mathrm{mM}$, Surface tension at $\mathrm{cmc}=38 \mathrm{mN} / \mathrm{m}$ $\beta_{\text {micelle }}=1.4, \beta_{\text {surface }}=1.5$ 


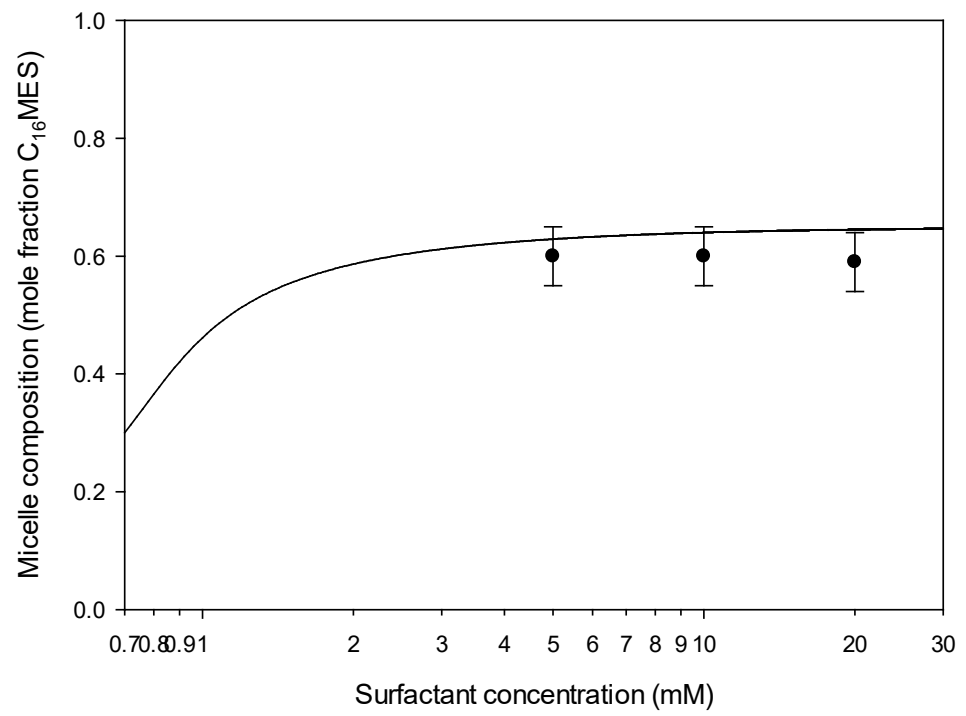

Figure 7. Variation in micelle composition with surfactant concentration for 65/35 mole

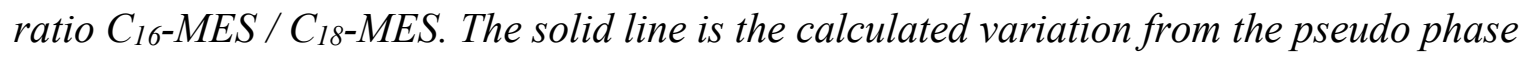
approximation for the parameters summarised in table 7.

In order to more fully understand the mixing properties at the surface and in micelles the data can be interpreted by two limiting approaches, a rigorous or approximate thermodynamic approach such as the pseudo phase approximation $(55,56)$ or using statistical mechanics, such as the molecular thermodynamic approach $(57,58)$. Here the surface and micelle compositions have been calculated using the pseudo phase approximation in which quadratic and cubic terms are included in the description of the excess free energy of mixing. Recent studies (59-61) have shown this approach to be particularly powerful in describing complex surfactant mixtures.

In the pseudo phase approximation, at equilibrium the chemical potential of the components of the pseudo phase, micelles, surface and solution monomer, are equal $(55,56)$; and equating the chemical potential of the micelle and monomer, for example, gives,

$$
x_{i}=\frac{c_{i}^{m o n}}{f_{i}^{m} c_{i}^{\mu}}
$$

where $\mathrm{x}_{\mathrm{i}}$ is the mole fraction of the $\mathrm{i}^{\text {th }}$ component in the micelle, $\mathrm{c}_{\mathrm{i}}^{\text {mon }}$ the monomer concentration of the $\mathrm{i}^{\text {th }}$ component, $\mathrm{f}_{\mathrm{i}}^{\mu}$ its activity coefficient in the micelle, and $\mathrm{c}_{\mathrm{i}}{ }^{\mu}$ its cmc. For a binary mixture, assuming the micelle mole fractions equal unity and at the cmc $c_{i}^{m o n}=\alpha_{i} c_{i}^{m i x}$, where $\alpha_{\mathrm{i}}$ is the mole fraction of monomer in solution and $\mathrm{c}^{\mu}{ }_{\text {mix }}$ the mixed cmc, 


$$
\frac{1}{c_{m i x}^{\mu}}=\frac{\alpha_{1}}{f_{1} c_{1}^{\mu}}+\frac{\alpha_{2}}{f_{2} c_{2}^{\mu}}
$$

The activity coefficients are derived from an expansion of the excess free energy of mixing, Ge, which includes quadratic and cubic terms in the form,

$$
G e=x_{1} x_{2} \beta_{12}+x_{1} x_{2}\left(x_{1}-x_{2}\right) C_{12}
$$

where $\beta_{12}$ and $C_{12}$ are the interaction constants. In the Regular Solution Approximation $C_{12}$ is zero. As described in detail elsewhere (59-61) this leads to a set of equations that can be solved iteratively to obtain the cmc variation, the variations in micelle compositions and the variation in surface and monomer concentrations below and above the $\mathrm{cmc}$. In the application of the PPS to the surface and micelle data presented here the same model parameters are constrained to model both data, and this provides a strong constraint on the parameters.

In figure $4 b$ the solid and dashed lines are the calculated variation in the surface composition using the PPA as described above. The key model parameters for the PPA calculations are summarised in table 7. Using the known cmc and surface tension values the data are within error well described using only the quadratic terms, $\beta_{12}$, in the expansion of the excess free energy of mixing. The analysis shows that at the surface, $\beta_{\mathrm{s}}=1.5$, and in the micelles, $\beta_{\mathrm{m}}=1.4$, with both cubic coefficients zero; that is, the interaction between the two surfactants is repulsive. The PPA analysis of the surface data provides a good description of the evolution in the surface composition with concentration, from below the cmc to concentrations well in excess of the cmc. The impact of the onset of micellisation on the surface composition is evident and the surface composition changes markedly at the cmc. Below the cmc the surface is in equilibrium with monomers in solution, whereas above the $\mathrm{cmc}$ the equilibrium changes and the surface and monomers are now in equlibrium with the micellar phase.

The corresponding variation in the micellar composition is shown in figure 7 , and within experimental error the data and calculations are in good agreement. The variation in the micellar composition with concentration, over the limited concentration range explored, is less marked. However the values show the expected trend, that as the solution concentration increases the micelle composition tends towards the solution composition.

Although over the concentration range measured the surface and micelle compositions are different to the solution composition, they are within the PPA predictions, and the micelle composition shows the expected trend towards the solution composition as the surfactant 
concentration increases. The surface and micelles have different compositions is not unusual or unexpected. Whereas the micelle composition must tend towards the solution composition in the limit of high concentrations, the surface does not have that constraint. The surface and monomer components can adopt a different composition as seen here, and as illustrated previously in non-ionic surfactant mixtures (50) and in non-ionic / anionic surfactant mixtures (51).

The observation of a repulsive interaction, positive interaction parameter, close to phase separation has important implications for the interpretation of eutectic surfactant mixtures. Moroi et al (36) investigated the phase equilibrium in mixtures of anionic surfactants, SDS with different divalent metal dodecyl sulfates, and the phase diagrams and Krafft point minima determined were ascribed to a eutectic point. Tsujii et al (37) investigated the Krafft point variations in the sodium and calcium salts of a range of different anionic surfactants, and in most cases a Krafft point minimum was obtained and interpreted in terms of eutectic mixtures. Scamehorn et al $(38,39)$ made similar observations on the behaviour of mixtures of anionic surfactants with different chain lengths and isomeric forms. Tsujii et al (37) interpreted the Krafft point as the melting temperature of the hydrated solid surfactant and hence the observed immiscibility was consistent with freezing point depression of the associated solid phases of the different components. Hence the Krafft point minimum was attributed to a eutectic point, and the usual thermodynamical treatment of freezing point depression was able to predict the Krafft point variation with composition. For two solids to form a simple eutectic requires that the pure solids are stable solid phases and a mixed solid phase does not form, and hence the immiscibility reported by Tsujii et al. The eutectic is then the result of each solid dissolving to form a dilute solution in the other as the liquid solvent. Since the solid phases are immiscible in a simple eutectic this implies a repulsive interaction between the two surfactants. The $\mathrm{C}_{16^{-}} /$ $\mathrm{C}_{18}$-MES mixture exhibits a Krafft point minimum (35). Furthermore we have demonstrated here that the surface and micelle mixing are consistent with a repulsive interaction, positive interaction parameter, which is close to phase separation. For example a positive interaction parameter of $\geq 2.0$ in the regular solution approximation results in phase separation. Hence the assumption made by Moroi et al (36), Tsujii et al $(37)$ and Scamehorn et al $(38,39)$ that the behaviour of mixtures like the $\mathrm{C}_{16^{-}} / \mathrm{C}_{18}$-MES mixture is analogous with eutectic behaviour seems well justified.

\section{CONCLUSIONS}


The NR and SANS measurements have extended greatly our understanding of the adsorption and self-assembly of the MES surfactant, and will provide the key information required for their wider exploitation as sustainable surfactants (13-26). The comparison of the adsorption isotherms of $\mathrm{C}_{14}$ to $\mathrm{C}_{18}$-MES, their scaling with their cmc values, and the invariance in the saturation adsorption reinforces the conclusions from previous studies on other anionic surfactants $(32,47)$ that the saturation adsorption or limiting area / molecule is determined by the alkyl chain packing and that the headgroup plays a more secondary role. The structure of the MES surfactant, which confers some tolerance to hardwater conditions (18-22), results in the inhibition of precipitation to a sufficient degree for the addition of multivalent counterions to induce surface multilayer formation and micellar growth. This is broadly similar to that observed for SLES $(29,30,53)$, and also extends earlier measurements on $\mathrm{C}_{14}$-MES (28). However, for the longer alkyl chain length surfactants, $\mathrm{C}_{16}, \mathrm{C}_{18}$-MES, the closer proximity of the precipitation boundary limits the range of surface structures observed and for $\mathrm{C}_{14}$ to $\mathrm{C}_{18^{-}}$ MES results in only nominal micellar growth before precipitation occurs. The Krafft point minimum reported for $\mathrm{C}_{16} / \mathrm{C}_{18}$-MES mixtures (35) extends significantly the potential application of the longer alkyl chain surfactants. The variation in the surface and micelle compositions determined here are well described by the pseudo phase approximation with repulsive interactions, positive interaction parameter, with values relatively close to those for phase separation. The repulsive interaction supports the analogy with eutectic mixtures (36-39) and explain the mixing properties of these and related surfactant mixtures.

\section{ACKNOWLEDGEMENTS}

The provision of beam time on the INTER reflectometer and the LOQ diffractometer at ISIS is acknowledged. The invaluable scientific and technical input and support from the staff at ISIS is greatly appreciated.

\section{SUPPORTING INFORMATION}

Additional tables are included in the Supporting Information 


\section{REFERENCES}

(1) J. J. Scheibel, The evolution of anionic surfactant technology to meet the requirements of the laundry detergent industry, J. Surf. Det. 2004, 7, 319-328

(2) Y U Yangxin, Z Jin, A E Bayley, Development of surfactants and builders in detergent formulations, Chinese J. Chem. Eng. 2008, 16, 517-527

(3) J F Scamehorn in "Phenomena in mixed surfactant systems", Ed J F Scamehorn, ACS Symp. Ser. 311, ACS Washington DC, 1988

(4) M J Rosen in "Phenomena in mixed surfactant systems", Ed J F Scamehorn, ACS Symp. Ser. 311, ACS Washington DC, 1988

(5) K L Steller, J F Scamehorn, Surfactant precipitation in aqueous solutions containing mixtures of anionic and non-ionic surfactants, J. Am. Oil Chem. Soc. 1986, 63, 566574

(6) P Paton-Morales, F I Talens-Alesson, Effect of ionic strength and competitive adsorption of $\mathrm{Na}^{+}$on the flocculation of Lauryl sulfate micelles with $\mathrm{Al}^{3+}$, Langmuir, $2001,17,6059-6064$

(7) B L Chou, J H Bae, Surfactant precipitation and redissolution in brine, J. Coll. Int. Sci. $1983,96,192-203$

(8) A Sein, J B F N Engberts, E van der Linden, J van der Pas, Lyotropic phase of dodecyl benzene sulfonates with different counterions in water, Langmuir, 1996, 12, 2913-2923

(9) R G Alargova, K D Danov, P A Kralchevsky, G Broze, A Mahreteab, Growth of giant rodlike micelles in ionic surfactants in the presence of $\mathrm{Al}^{3+}$ counterions, Langmuir, $1998,14,4036-4049$

(10) R G Alargova, V P Ivanova, P A Kralchevsky, A Mahreteab, G Broze, Growth of rodlike micelles in anionic surfactant solutions in the presence of $\mathrm{Ca}^{2+}$ counterions, Coll. Surf. A 1998, 142, 201-218

(11) $\mathrm{J} \mathrm{H} \mathrm{Mu}, \mathrm{G} \mathrm{Z} \mathrm{Li}$, Rheology of viscoelastic anionic micellar solutions in the presence of multivalent counterions, Coll. Polym. Sci. 2001, 279, 872-875

(12) I Johansson, M Svensson, Surfactants based on fatty acids and other natural hydrophobes, Curr. Opin. Coll. Int. Sci. 2001, 6, 178-188

(13) Z A Maurad, R Ghazali, P Siwayanan, Z Ismail, S Ahmad, $\alpha$-sulfonated methyl esters as an active ingredient in palm-based powder detergents, J. Surf. Det. 2006, 9, $161-167$ 
of the production process of $\alpha$-methyl ester sulfonates, Bioresource Technol. 2010, 101, $8762-8771$

S Ahmad, P Siwayanan, H A Murad, H A Aziz, H Seng Soi, Beyond biodiesel, methyl esters as a route for the production of surfactant feedstocks, Inform, 2007, 18, $216-228$

(16) L Cohen, F Soto, M S Imura, Separation and extraction of $\phi$ methyl ester sulfonates: new features, J. Surf. Det. 2001, 4, 73-74

(17) W Stein, H Haumann, $\alpha$-sulfonated fatty acids and esters: manufacturing, process, properties and applications, JAOCS, 1975, 52, 323-329

J Aparicio, B W MacArthur, W B Sheats, B J Brooks, MES-myths, mysteries and perspective on properties and use, ICSD, 2012, Shanghai, PRC

D W Roberts, Aquatic toxicity - are surfactant properties relevant, J. Surf. Det. 2000, 3, 309-315

(20) R Ghazali, Z A Maurad, P Siwayanan, M Yusof, A Ahmad, Assessment of aquatic effects on palm-based $\alpha$-sulfonated methyl esters, J. Oil Palm Res. 2006, 18, $225-230$

(21) R Ghazali, A Ahmad, Biodegradability and ecotoxicity of palm stearin based methyl ester sulfonates, J. Oil Palm Res. 2004, 16, 39-44

(22) R Ghazali, The effect of disalt on the biodegradability of methyl ester sulfonates, MES, J. Oil Palm Res. 2002, 14, 45-50

(23) L Cohen, F Trujillo, Synthesis, characterisation and surface properties of sulfonated methyl esters, J. Surf. Det. 1998, 1, 338-341

(24) K Ohbu, M Fujiwara, Y Abu, Physicochemical properties of $\alpha$-sulfonated fatty acid esters, Prog. Coll. Polym. Sci. 1998, 109, 85-92

(25) S P Wong, W H Lim, S F Cheng, C H Chuah, Properties of sodium methyl ester 4-sulfoalkylate / trimethyl ammonium bromide mixtures, J. Surf. Det. 2012, 15, 601611

K D Danov, R D Stanimirova, P A Kralchevsky, E S Basheva, V I Ivanova, J T Petkov, Sulfonated methyl esters of fatty acids in aqueous solution: interfacial and micellar properties, J. Coll. Int. Sci. 2015, 457, 307-318

H Xu, P X Li, K Ma, R Welbourn, J Penfold, D W Roberts, R K Thomas, J T Petkov, Adsorption of methyl ester sulfonate at the air-water interface: can limitations 
in the application of the Gibbs equation be overcome by 'computer purification', Langmuir, 2017, 33, 9944-9953

H Xu, R K Thomas, J Penfold, P X li, K Ma, R Welbourn, D W Roberts, J T

Petkov, The impact of electrolyte on the adsorption of the anionic surfactant methyl ester sulfonate ate the air-solution interface: surface multilayer formation, J. Coll. Int. Sci. 2017, 512, 231-238

J Penfold, R K Thomas, C C Dong, I Tucker, K Metcalfe, S Golding, I Grillo, Equilibrium surface adsorption behaviour in complex anionic / non-ionic surfactant mixtures, Langmuir, 2007, 23, 10140-10149

J T Petkov, I M Tucker, J Penfold, R K Thomas, D N Petsev, C C Dong, S

Golding, I Grillo, The impact of multivalent counterions $\mathrm{Al}^{3+}$ on the surface adsorption and self-assembly of the anionic alkyloxyethylene sulfate and anionic / non-ionic surfactant mixtures, Langmuir, 2010, 26, 16691-16709

H Xu, J Penfold, R K Thomas, J T Petkov, I Tucker, J R P Webster, The formation of surface multilayers at the air-water interface from sodium polyethylene glycol monoalkyl ether sulfate / $\mathrm{AlCl}_{3}$ solutions: the role of the size of the polyethylene oxide group, Langmuir, 2013, 29, 11656-11666

H Xu, J Penfold, R K Thomas, J T Petkov, I Tucker, J R P Webster, The formation of surface multilayers at the air-water interface from sodium polyethylene glycol monoalkyl ether sulfate / $\mathrm{AlCl}_{3}$ solutions: the role of the alkyl chain length, Langmuir, 2013, 29, 12744-12753

R Bradbury, J Penfold, R K Thomas, I M Tucker, J T Petkov, C Jones, Enhanced perfume delivery to interfaces using surface multilayer structures, J. Coll.Int. Sci. 2016, 463, 199-206

(34) T Satsuki, Applications of MES in detergents, Inform, 1992, 3(10), 1099

(35) F Schambil, M J Schwuger, Physical-chemical properties of $\alpha$-sulfo fatty acid methyl esters and $\alpha$-sulfo fatty acid disalts, Tenside, 1990, 27, 380-385

(36) Y Moroi, T Oyama, R Matuura, Phase equilibria of anionic surfactant mixtures in aqueous solution, J. Coll. Int. Sci. 1977, 60, 103-111

(37) K Tsujil, N Salto, T Takesuchi, Krafft points of anionic surfactants and their mixtures with the special attention to their applicability in hard water, J. Phys. Chem. $1980,84,2287-2291$ 

page 203, in Mixed Surfactant systems, Eds K Ogino, M Abe, Surfactant Science Series, Vol 46, Marcel Dekker, NY, 1992

(39) J F Scamehorn, J H Harwell, Chapt 18, page 601, Mixed Surfactant Systems, Surfactant Science Series, Eds M Abe, J F Scamehorn, Marcel Dekker, NY, 2005 optimising the thermal properties and thermal conductivity of myristic acid / palmitic acid eutectic mixtures with acid based surfactants, Appl. Thermal Eng. 2013, 60, 261265 INTER reflectometer at the ISIS Facility, http://www.isis.stfc.ac.uk/instruments/INTER

(42) J R Lu, R K Thomas, J Penfold, Surfactant layers at the air-water interface: structure and composition, Adv. Coll. Int. Sci. 2000, 84, 143-304

LOQ diffractometer at the ISIS facility,

\section{http://www.isis.stfc.ac.uk/instruments/LOQ}

(44) R K Heeenan, S M King, R Osborn, H B Stanley, RAL Internal report, RAL89-128, 1989

(45) J B Hayter, J Penfold, Determination of micelle structure and charge by SANS, Coll. Polym. Sci. 1983, 26, 1022-1030

(46) J B Hayter, J Penfold, An analytic structure factor for macrion solutions, Mol. Phys. 1981, 42, 109-118

(47) I Varga, R Meszaros, T Gilanyi, Adsorption of sodium alkyl sulfate homologues at the air/solution interface, J. Phys. Chem. B, 2007, 111, 7160-7168

(48) MB11a subroutine in the Harwell Subroutine Library. www.hs1.rl.ac.uk

(49) J H Clint, Micellisation in mixed non-ionic surface active agents, J. Chem. Soc.

Faraday Trans. I, 1975, 71, 1327-1334

(50) J Penfold, E Staples, L Thompson, I Tucker, The composition of non-ionic surfactant mixtures at the air-water interface as determined by neutron reflectivity, Coll. Surf. 1995, 102, 107-132

(51) J Penfold, R K Thomas, J R Lu, Solution and adsorption behaviour of the mixed surfactant system SDS / $\mathrm{C}_{12} \mathrm{E}_{6}$, Langmuir, 1995, 11, 2496-2508 
J B Hayter, A self-consistent theory of dressed micelles, Langmuir, 1992, 8, 2873-2876

(53) H Xu, J Penfold, R K Thomas, J T Petkov, I Tucker, A Terry, The impact of $\mathrm{AlCl}_{3}$ on the self-assembly of the anionic surfactant sodium oligoethylene glycol monoalkyl ether sulfate in aqueous solution, Langmuir, 2013, 29, 13359-13366

$\mathrm{H} \mathrm{Xu}, \mathrm{P} \mathrm{X} \mathrm{Li}, \mathrm{K}$ Ma, R K Thomas, J Penfold, J R Lu, Limitations in the application of the Gibbs equation to anionic surfactants at the air-water interface: sodium dodecylsulfate and sodium dodecylmonooxyethylenesulfate above and below the cmc, Langmuir, 2013, 29, 9335-9351

(55) P M Holland, Non-ideal mixed micelle solutions, Adv. Coll. Int. Sci. 1986, 26, $111-129$

(56) P M Holland, D N Rubingh, Non-ideal multicomponent mixed micelle model, J. Phys. Chem. 1983, 87, 1984-1990

(57) R Nagarajan, E Ruckenstein, Theory of surfactant self-assembly, a predictive molecular thermodynamic approach, Langmuir, 1991, 7, 2934-2969

(58) A Shiloach, D Blankschtein, Predicting micellar solution properties in binary surfactant mixtures, Langmuir, 1998, 14, 1618-1638

(59) P X Li, K Ma, R K Thomas, J Penfold, Analysis of the asymmetrical synergy in the adsorption of zwitterionic-ionic surfactant mixtures at the air-water interface below and above the cmc, J. Phys. Chem. B, 2016, 120, 3677-3691

(60) J Liley, R K Thomas, J Penfold, I M Tucker, J T Petkov, P Stevenson, J R P Webster, Surfactant adsorption in ternary surfactant mixtures above the $\mathrm{cmc}$; the importance of the shape of the excess free energy, J Phys. Chem. B, 2017, 121, 28252838

(61) J Liley, R K Thomas, J Penfold, I M Tucker, J T Petkov, P Stevenson, J R P Webster, The impact of electrolyte on the adsorption at the air-water interface for a ternary surfactant mixture above the cmc, Langmuir, 2017, 33, 4301-4312 


\section{SUPPORTING INFORMATION}

\section{TABLES}

Table S1. Adsorption isotherm data for $C_{16}, C_{18}-M E S$ in figure 2 from NR data (a) $C_{16-M E S}$

\begin{tabular}{|c|c|c|c|c|}
\hline $\begin{array}{c}\text { Surfactant } \\
\text { concentration } \\
(\mathbf{m M})\end{array}$ & d $( \pm 1 \AA)$ & $\begin{array}{c}\rho\left( \pm 0.05 \times 10^{-6}\right. \\
\left.\AA^{-2}\right)\end{array}$ & $A\left( \pm 2 \AA^{2}\right)$ & $\begin{array}{l}\Gamma\left( \pm 0.1 \times 10^{-}\right. \\
\left.10 \mathrm{~mol} \mathrm{~cm}^{-2}\right)\end{array}$ \\
\hline 0.1 & 17 & 2.5 & 80 & 2.1 \\
\hline 0.3 & 18 & 3.15 & 59 & 2.9 \\
\hline 0.5 & 21 & 2.9 & 54 & 3.1 \\
\hline 0.7 & 19 & 3.4 & 52 & 3.2 \\
\hline 1.0 & 19 & 3.4 & 52 & 3.2 \\
\hline 1.5 & 19 & 3.3 & 52 & 3.2 \\
\hline 2.0 & 19 & 3.4 & 52 & 3.2 \\
\hline
\end{tabular}

(b) $C_{18}-M E S$

\begin{tabular}{|c|c|c|c|c|}
\hline $\begin{array}{c}\text { Surfactant } \\
\text { concentration } \\
(\mathbf{m M})\end{array}$ & d ( $\pm 1 \AA)$ & $\begin{array}{c}\rho\left( \pm 0.05 \times 10^{-6}\right. \\
\left.\AA^{-2}\right)\end{array}$ & $A\left( \pm 2 \AA^{2}\right)$ & $\begin{array}{c}\Gamma\left( \pm 0.1 \times 10^{-}\right. \\
\left.10 \mathrm{~mol} \mathrm{~cm}^{-2}\right)\end{array}$ \\
\hline 0.1 & 19 & 3.0 & 64 & 2.6 \\
\hline 0.2 & 20 & 3.65 & 51 & 3.3 \\
\hline 0.3 & 20 & 3.8 & 50 & 3.3 \\
\hline 0.5 & 19 & 4.0 & 50 & 3.3 \\
\hline
\end{tabular}

$d$ and $\rho$ are the adsorbed monolayer thicknesses and scattering length density, $A$ the area/molecule and $\Gamma$ the adsorbed amount (as defined in equations 1 and 2 in the main text) 